\title{
Future Earth and EcoHealth: A New Paradigm Toward Global Sustainability and Health
}

Concurrent with the sustainable development goals adoption and the UN Climate negotiations, 2015 also marked the formal establishment of the Future Earth scientific platform, envisioned as a 10-year research program for global sustainability. Future Earth merges previous scientific programs in the global environmental change realmincluding biodiversity science from DIVERSITAS, the International Geosphere-Biosphere Programme, and the International Human Dimensions Programme.

The merging of programs offers a way to reduce redundancy, but even more powerfully, a way to bring together seemingly disparate facets of global change research communities to work more collaboratively. Accordingly, Future Earth seeks to encourage fundamental scientific work, integrate sciences across disciplines, especially incorporating the social sciences, humanities, and health and engineering sciences. It also seeks co-designing science projects with stakeholders such as users and funders to develop solutions oriented research. We intend to catalyze new relationships and a new model for research. A key to our success is co-design and co-production of knowledge- the upfront joint creation of research questions that can lend more ready application of findings by potential users. Governments, industry, and civil society are our key stakeholders.

Future Earth is not starting from scratch; it is built on the existing critical research that has shown the many effects of anthropogenic forces on our health and environment and the need for action. Through its core projects, it maintains the importance of continued fundamental scientific knowledge generation. Research is spread across three themes-'Dynamic Planet,' 'Global Sustainable Development,' and 'Transformations Toward Sustainabil- ity,' that will collectively enable a sustainable global society. Future Earth's ambitious approach will require research to evolve to a more full-spectrum research-to-results approach.

The unique structure of Future Earth facilitates its innovative goals. It is sponsored by the Science and Technology Alliance for Global Sustainability, which consists of the International Council for Science, International Social Science Council, the Belmont Forum, the United Nations Environment Program, UNESCO, United Nations University, and World Meteorological Organizations. A Scientific Committee oversees research priorities, and an Engagement Committee provides information dissemination and application expertise. A globally distributed Executive Secretariat consisting of five Global Hubs and four Regional Centres supports global research support. Publications are encouraged to be open access, and projects are challenged to present their research in new formats and to provide capacity building opportunities. Social sciences, humanities, law, and even the arts have key roles in understanding anthropogenic influences warranting greater integration into research (Cornell et al. 2013).

Health is a major priority under Future Earth, as articulated in its Strategic Research Agenda, and inherent in discussions on water, food, agriculture, urbanization, and other co-pressures the planet is contending with. We encourage an eco-social view of health that sees it not only as a disease of individual organisms, but more importantly as a result of the ecological and social conditions of our life, work, transportation, entertainment, and the unity of health of humans, animals, and other planetary species (Future Earth 2014). The ecoHEALTH project, which originated under DIVERSITAS, serves as a core project in 
Future Earth, exploring links between global environmental change and health. Toward this goal, the project's scientific analyses and policy outreach have emphasized how health can be leveraged as motivation to address the underlying drivers of disease-many which also correlate with biodiversity loss, climate change, and other planetary pressures. The ecoHEALTH Scientific Steering Committee includes experts on ecology, public health, agriculture, conservation, international development, virology, economics, and weather and climate science. Representation spans academic, national, and intergovernmental institutions, providing not only critical insight and diverse perspectives, but also a degree of direct application for both capacity building and policy change.

In addition to the ecoHEALTH project, the wider EcoHealth community offers many examples of effective collaboration across ecology and health disciplines, as well as social and environmental justice, conservation, and agriculture. The recent release of the Convention on Biological Diversity-World Health Organization's Connecting Global Priorities: Biodiversity and Human Health-A State of Knowledge Review and the Lancet Commission on Planetary Health report provides synthesis of knowledge generated to date, along with a strong call to action to mobilize, reinforcing the need for coordinated ecology and health understanding and firmly stating potential synergies. In June 2015, the Science and Engagement Committees of Future Earth approved the creation of several Knowledge Action Networks (KANs) to address the eight challenges of our Vision 2025. One of these KANs focuses on Health. It will bring together researchers, communities of practice, and stakeholders to study and develop actionable sciencebased solutions to the complex nexus of environment and health.

With this momentum, what can we do to ensure our research finds actionable use toward a 'future health' that we want for our planet? We encourage our community to collectively stretch the boundaries of what we consider research, exploring non-traditional research partnerships and mechanisms for policy and other societal application. Critically, our community can continue to reinforce the benefits of shifting from single-species perspectives to ecosystems-level understanding, as well as moving from reactive, resource-intensive responses to proactive, pre- ventive health and environmental systems. Pairing our findings with economic analyses can drive home the "bottom-line" of our science for policy makers. Through participation in national and regional Future Earth and other environmental change and sustainability initiatives, we can guide research priorities and study designs-for example, for observation systems that track long-term disease ecology dynamics, including pre- and post-studies at development sites to measure potential changes. These can be utilized for collection of additional data relevant to environmental change, such as species composition and abundance and ecosystem integrity monitoring.

While we should pursue multiple avenues for change, we hope that Future Earth will help launch a new era in research that embraces innovation for social and ecological good. The environmental challenges and associated health risks we face are immense, and to mitigate or overcome them requires major scientific and societal achievements on a scale perhaps not yet seen before. Values must shift to meet true needs for research and solutions, not disciplinary confines, with unprecedented openness of collaboration. Imagine what our potential can be!

Catherine C. Machalaba, Peter Daszak, and William B. Karesh

Future Earth ecoHEALTH Project, c/o EcoHealth Alliance, 460 West 34th Street, 1701, New York, NY 10001, USA e-mail: machalaba@ecohealthalliance.org

Paul Shrivastava

Future Earth, Suite 1020, 1250 Guy Street, Montreal, Quebec H3H 2T4, Canada

\section{REFERENCES}

Cornell S, Berkhout F, Tuinstra W, Tàbara JD, Jäger J, Chabay I, de Wit B, Langlais R, Mills D, Moll P, Otto IM, Petersen A, Pohl C, van Kerkhoff L (2013) Opening up knowledge systems for better responses to global environmental change. Environmental Science \& Policy 28:60-70

Future Earth (2014) Future Earth Strategic Research Agenda 2014. Paris: International Council for Science (ICSU). http://www. futureearth.org/sites/default/files/strategic_research_agenda_2014.pdf.

Published online: December 2, 2015 